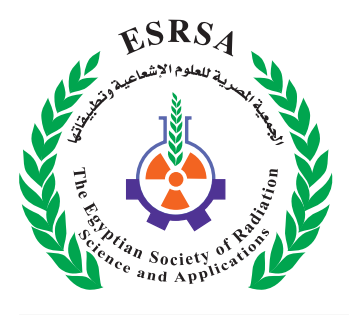

J. Nucl. Tech. Appl. Sci., Vol. 8, PP. 113 : 118 (2020)

\title{
Irradiation Embrittlement of WWER RPV Steels Irradiated at High Fluences
}

Kryukov, A.*; Rubtsov, V. and Lebedinsky, V.

Received: 30/06/2020

Accepted: 09/08/2020

DOI: $10.21608 /$ jntas.2020.34215.1023

\section{ABSTRACT}

E.mail:kryukov@secnrs.ru

A statistical analysis of data obtained during impact testing of surveillance specimen of 15 WWER-440 RPVs operating in Russia, Ukraine, Armenia, Hungary, the Czech Republic and Slovakia was performed. The raw data used were selected from the IAEA Intera national Database. As a result of the analysis, the influence of $\mathrm{P}$ and $\mathrm{Cu}$ to $\mathrm{T}_{\mathrm{k}}$ increase was observed at a fluence up to $5 \times 10^{20} \mathrm{~cm}^{-2}(\mathrm{E}>$ $0.5 \mathrm{MeV}$ ), more than double design end of life WWER-440 fluence value. A proposal to increase the application range of normative det pendences $\Delta \mathrm{T}_{\mathrm{k}}(\mathrm{F})$ on reactor pressure vessel from $3 \times 10^{20} \mathrm{~cm}^{-2}$ to $5 \times 10^{20} \mathrm{~cm}^{-2}$ has been prepared to amend the regulatory and technical documents regarding the adjustment of the residual life of WWER-440 RPVs. It will allow the WWER-440 RPV to be operated for 60-80 years without annealing the base metal and in some cases without annealing the irradiated welds.

1. Scientific and Engineering Centre for Nuclear and Radiation Safety, Russia, Moscow, 107140, Malaya Krasnoselskaya st. $28 /$, bld. 5. 


\section{RELEVANCE OF EMBRITTLEMENT AS- SESSMENT AT HIGH NEUTRON FLU- ENCE}

At present, the irradiation embrittlement assessment of WWER-440 Reactor Pressure Vessel (RPV) materials in Russia is carried out in accordance with the regulatory guide (PNAE G-7-002-86) and code (MT 1.2.1.15.0232-2014). Paragraph 4.5 (MT 1.2.1.15.0232-2014) indicates that this code is applicable to justify the operation of the reactor vessel to a maximum neutron fluence of $3.0 \times 10^{20} \mathrm{~cm}^{-2}(\mathrm{E}>0.5$ $\mathrm{MeV})$. Such fluence value on the inner surface of the WWER-440 RPV wall was established in the $70 \mathrm{~s}$, based on an analysis of the experimental data available at that time on radiation embrittlement of 15Kh2MFA steel (the base metal of the WWER-440 RPV) and its weld metal made with 10KHNMT and 10KHNMTU welding wires (Amaev et al., 1993), (Alekseenko et al., 1997). The following design values of the neutron fluence for the WWER-440 RPV were established in the design of the reactor:

$-2.4 \times 10^{20} \mathrm{~cm}^{-2}$ for the base metal;

$-1.8 \times 10^{20} \mathrm{~cm}^{-2}$ for weld metal.

Resistance to brittle fracture of materials of WWER-440 RPV was justified before reaching the above design values of neutron fluence. It should be noted that in the 70s there was very limited information on the radiation stability of steels irradiated at $270^{\circ} \mathrm{C}$ with fluences exceeding the mentioned design values.

At present, the operational life of WWER-440 has significantly exceeded its design values (3040 years), and neutron fluences on the RPVs are approaching the maximum value allowed by current regulatory and technical documents, namely $3.0 \times 10^{20} \mathrm{~cm}^{-2}$. For further safe operation of WWER440 in terms of providing resistance to brittle fracture of the RPV materials, there are several options.

The irradiation embrittlement can be mitigated by reducing the neutron fluence to the RPV wall by low-leakage fuel management and replacing the peripheral fuel assemblies by dummy assemblies.

A significant mitigation of the RPV steel radiation embrittlement by thermal annealing (Kryukov et al., 2012; Fedotova et al., 2018). Annealing of WWER-440 RPV has been successfully implemented since 1987. To date, more than 20 RPVs have been annealed in Russia and abroad. However, there is a probability of forming the grain boundary phosphorus segregations in metal at the high temperature annealing.

In turn, the results of surveillance specimen tests of the base metal and welds of WWER-440 RPV steels with a low content of copper and phosphorus show that the radiation embrittlement of steel at fluences of $\sim 3 \times 10^{20} \mathrm{~cm}^{-2}$ is significantly lower than the allowable values, and in this case, annealing is not required (Kryukov et al., 2014; Margolin et al., 2013).

In addition, the annealing of the irradiated base metal, rather than the weld, increases the annealed zone of the RPV several times, which leads to the need to develop and manufacture a new annealing device, as well as to carry out additional work to justify the strength of the equipment during annealing.

An alternative way to annealing the entire irradiated part of the RPV is to justify required radiation stability of RPV steels, primarily the base metal, irradiated with neutron fluences exceeding $3 \times 10^{20}$ $\mathrm{cm}^{-2}$.

For this, first of all, it is necessary to analyze the experimental data on the radiation embrittlement of RPV steels with a low content of copper and phosphorus irradiated with fluences higher than $3.0 \times 10^{20}$ $\mathrm{cm}^{-2}$. The most representative to achieve this goal are the surveillance specimen test results. In the framework of this work, a statistical analysis of the data obtained during impact testing of surveillance specimen of 15 WWER-440 RPVs operating in Russia, Ukraine, Armenia, Hungary, the Czech Republic and 
Slovakia was performed. The raw data used for the analysis were extracted from the IAEA International Database of RPV materials (Gillemot, 1995).
The surveillance test results analyzed in this work were splitted into 4 groups, which are listed in Table 1.

Table (1) : Ranking of WWER-440 RPV surveillance test results based on the content of phosphorus and copper.

\begin{tabular}{|c|c|c|}
\hline Group of steels & Phosphorus content, \% & Cupper content, \% \\
\hline "Clean “ & $\mathrm{P} \leq 0.012$ & $\mathrm{Cu} \leq 0.07$ \\
\hline "Almost clean“ & $0.017 \geq \mathrm{P} \geq 0.012$ & $0.14 \geq \mathrm{Cu} \geq 0.07$ \\
\hline "Dirty“ & $0.036 \geq \mathrm{P} \geq 0.028$ & $\mathrm{Cu} \geq 0.13$ \\
\hline "Highly dirty“ & $\mathrm{P}>0.036$ & $\mathrm{Cu}>0.13$ \\
\hline
\end{tabular}

\section{Experimental data analysis}

As indicated above, the aim of this work is to develop proposal for updating the regulatory and technical documentation (PNAE G-7-002-86), (MT 1.2.1.15.0232-2014) to assess the residual life of WWER-440 RPVs based on increasing the allowable neutron fluence affecting the reactor pressure vessel during operation. To do this, it is needed to set the target value of the fluence, relative to which the degree of radiation embrittlement of the metal is estimated. Based on the design fluence of $2.4 \times 10^{20}$ $\mathrm{cm}^{-2}$ given above for the base metal corresponding to 40 years of operation of WWER-440, the target fluence value is defined as $5 \times 10^{20} \mathrm{~cm}^{-2}$. The indicated value approximately corresponds to the maximum fluence on the inner surface of the WWER-440 RPV just opposite the center of the core with full fuel loading over 80 years of operation.

In connection with the foregoing, an assessment was made of the radiation embrittlement of RPV steels under irradiation up to $5 \times 10^{20} \mathrm{~cm}^{-2}$.

Figure 1 shows the dependences of $\Delta \mathrm{T}_{\mathrm{k}}$ on fluence obtained from surveillance specimens irradiated up to a fluence of $5 \times 10^{20} \mathrm{~cm}^{-2}$ for the groups of materials listed in Table 1. It should be noted that the plots of the $T_{k}$ shifts presented in Figure 1 versus the fluence are determined by the least square method and characterize the average changes in the Tk as a result of irradiation.

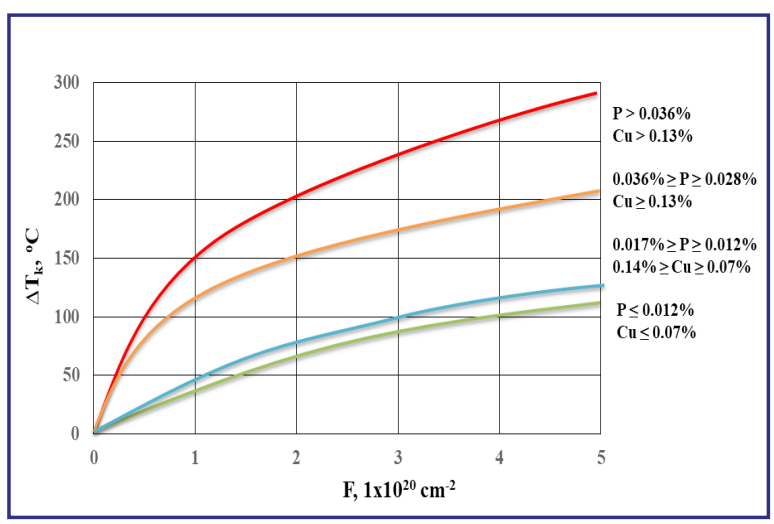

Fig. (1): Irradiation embrittlement of WWER-440 RPV surveillance specimens at high neutron fluence.

From Figure 1 it follows that for "dirty" and "very dirty" steels the $\Delta \mathrm{T}_{\mathrm{k}}$ is $170^{\circ} \mathrm{C}$ and higher at a fluence of $\sim 3 \times 10^{20} \mathrm{~cm}^{-2}$. Then for these two groups of steels the evaluation of $\Delta \mathrm{T}_{\mathrm{K}}$ at higher fluences is not of practical importance.

As for the "clean" and "almost clean" steels, a more detailed statistical analysis of the experimental data was performed, the results of which are presented in Figures 2-3. 


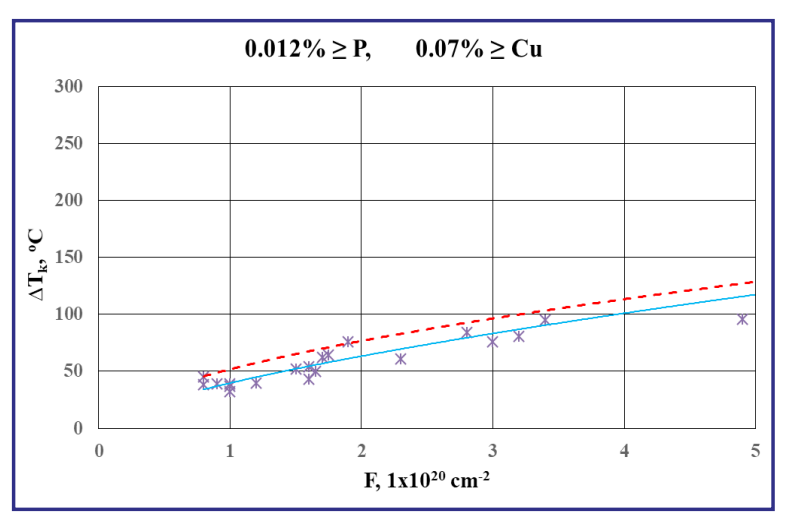

Fig. (2): Irradiation embrittlement of WWER-440 RPV "clean" steels at high neutron fluence (average increase, upper limit of $95 \%$ confidence interval.

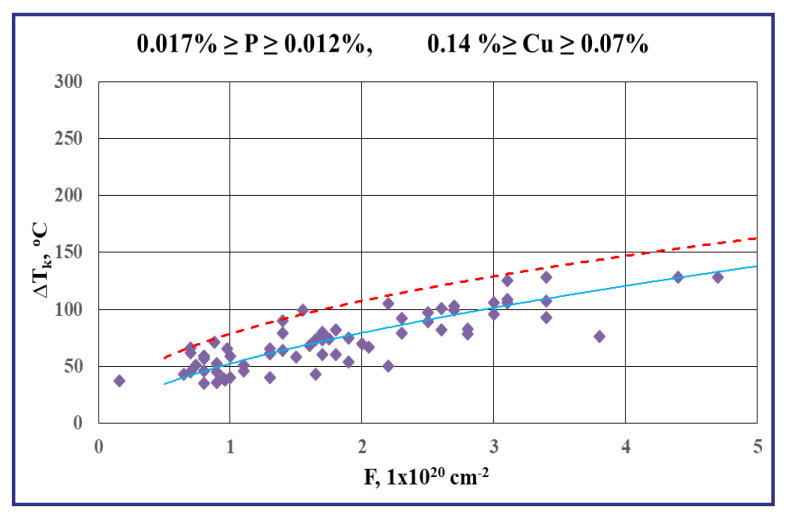

Fig. (3): Irradiation embrittlement of WWER-440 RPV "almost clean" steels at high neutron fluence (average increase, upper limit of $95 \%$ confidence interval.

The average increase in $\Delta \mathrm{T} \kappa$ under irradiation for "clean" steels, presented in Figure 2, are described by the dependence:

$$
\Delta T_{k}=39,707 \cdot\left(\frac{F}{10^{20}}\right)^{0,6728}
$$

and the data shown in Figure 3 related to "almost clean" materials are described by the dependence:

$$
\Delta T_{k}=52,184 \cdot\left(\frac{F}{10^{20}}\right)^{0,6042}
$$

In order to determine the $95 \%$ confidence interval, the upper limit of which is shown in Figures 2-3, the standard deviations $\sigma$ are calculated, which at a fluence of $5 \times 10^{20} \mathrm{~cm}^{-2}$ are 7.4 and $11.4^{\circ} \mathrm{C}$ for "clean" and "almost clean" steels, respectively.
Taking into account that the upper limit of the $95 \%$ confidence interval is higher than the average $\Delta \mathrm{T}_{\mathrm{K}}$ value by $2 \sigma$, the increase in $\mathrm{T}_{k}$ because of irradiation of WWER-440 RPV steels with fluences up to $5 \times 10^{20} \mathrm{~cm}^{-2}$ with a probability of $95 \%$ will not exceed:

$$
\begin{aligned}
& -\quad 132^{\circ} \mathrm{C} \text { for "clean" }(\mathrm{P} \leq 0.012 \%, \mathrm{Cu} \leq 0.07 \%) \\
& \text { steels, } \\
& -\quad 161^{\circ} \mathrm{C} \text { for "almost clean" }(0.012 \% \leq \mathrm{P} \leq 0.017 \\
& \%, 0.07 \% \leq \mathrm{Cu} \leq 0.14 \%) \text { steels. }
\end{aligned}
$$

It should be noted that according to the classification used in this paper, the base metal of all WWER-440 RPVs is classified as "pure" and "almost pure" materials.

Since, according to (PNAE G-7-002-86), the $\mathrm{T}_{\mathrm{k}}$ of the base metal in the unirradiated state $\mathrm{T}_{\mathrm{ko}}=$ $0^{\circ} \mathrm{C}$, and in practice below minus $30-40^{\circ} \mathrm{C}$, then the absolute value Tk of "clean" base metal after irradiation with a fluence of $\sim 5 \times 10^{20} \mathrm{~cm}^{-2}$ will not exceed $132^{\circ} \mathrm{C}$. Calculation results for resistance to brittle fracture of RPV using this $T_{k}$ value indicates that the WWER-440 RPV can be used for up to 80 years without annealing the base metal.

As for the welds, the $\mathrm{T}_{\mathrm{ko}}$ of which, as a rule, is higher than the base metal, for each specific RPV, it is necessary to calculate the resistance to brittle fracture of the weld metal based on the specific values of the fluence and the content of copper and phosphorus in the steel.

As mentioned above, at present, the WWER-440 RPV integrity assessment is carried out in accordance with (PNAE G-7-002-86), (MT 1.2.1.15.02322014). In paragraph 4.5 (MT 1.2.1.15.0232-2014) it is indicated that fracture toughness evaluation method is applicable to justify the operation of the pressure vessel to a maximum neutron fluence of $3 \times 10^{20}$ $\mathrm{cm}^{-2}$. Based on the statistical analysis of surveillance test results performed in this work, it is recommended to expand the range of application of the code 
(MT 1.2.1.15.0232-2014) to a maximum fluence of $5 \times 10^{20} \mathrm{~cm}^{-2}$.

Increasing the maximum fluence to $5 \times 10^{20} \mathrm{~cm}^{-2}$ will allow to operate the WWER-440 RPVs up to 60-80 years without annealing the base metal, and in some cases without annealing the irradiated welds.

The dependence of the yield strength increase $\left(\Delta \mathrm{Rp}_{0.2}\right)$ versus neutron fluence for several surveillance sets of base metal and weld with low $\mathrm{P}$ and $\mathrm{Cu}$ contents in the fluence range from 0.5 to $15 \times 10^{20}$ $\mathrm{cm}^{-2}(\mathrm{E}>0.5 \mathrm{MeV})$ is presented in Fig. 4.

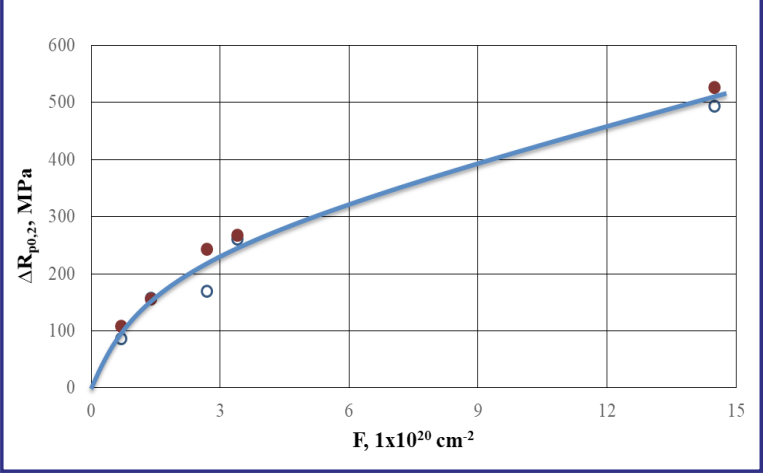

Fig. (4): Dependence of yield strength increase versus neutron fluence $(\circ-$ base metal, $\bullet$ - weld).

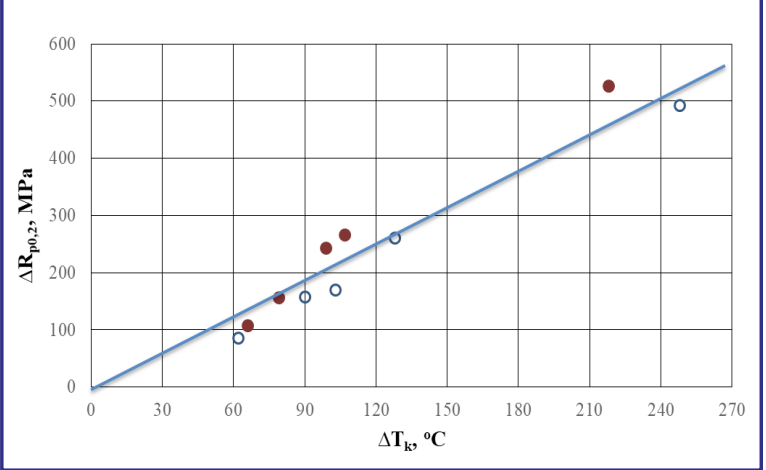

Fig. (5): Correlation of Tk shift and yield strength increase for steels with low $\mathrm{P}$ and $\mathrm{Cu}$ contents ( $\mathrm{O}$ - base metal, $\bullet-$ weld).

The linear relationship between $\Delta \mathrm{Tk}$ and $\Delta \mathrm{R}_{\mathrm{p} 0,2}$ indicates that radiation hardening remains the dominant radiation embrittlement mechanism at high neutron fluences. The relative contribution of nonhardening mechanism does not change up to fluence
$5 \times 10^{20} \mathrm{~cm}^{-2}$ at least for "clean" and "almost clean" steels.

\section{CONCLUSION AND PROPOSAL}

A statistical analysis of surveillance data from the International Database of RPV materials on the assessment of irradiation embrittlement of WWER440 RPV steel irradiated at high neutron fluences was done.

As a result of the analysis, the influence of $\mathrm{P}$ and $\mathrm{Cu}$ to $\mathrm{T}_{\mathrm{k}}$ increase was observed at a fluence up to 5 $x 10^{20} \mathrm{~cm}^{-2}(\mathrm{E}>0.5 \mathrm{MeV})$, more than double design end of life WWER-440 fluence value.

Based on these results, a proposal has been prepared to amend the regulatory and technical documents regarding the adjustment of the residual life of WWER-440 RPVs, namely, it is proposed to increase the application range of normative dependences $\Delta \mathrm{T}_{\mathrm{k}}(\mathrm{F})$ on reactor pressure vessel from $3 \mathrm{x}$ $10^{20} \mathrm{~cm}^{-2}$ to $5 \times 10^{20} \mathrm{~cm}^{-2}$.

Increasing the maximum fluence to $5 \times 10^{20} \mathrm{~cm}^{-2}$ will allow the WWER-440 RPV with relatively low impurity contents (P0.017\% and $\mathrm{Cu} 0.14 \%$ ) to be operated for 60-80 years without annealing the base metal, and in some cases without annealing the irradiated welds.

\section{REFERENCES}

- PNAE G-7-002-86 (1989): Rules of strength calculation for equipment and pipelines of nuclear power plants, Energoatomizdat, Moscow,

- MT 1.2.1.15.0232-2014 (2014): Fracture toughness calculation for 65 years lifetime extension of WWER440 RPV, Concern Rosenergoatom, Moscow.

- Amaev, A.; Kryukov, A.; Levit, V. and Sokolov, M. (1993): Radiation Stability of VVER-440 Vessel Materials, ASTM STP 1170, 4: 9.

- Alekseenko, N.; Amaev, A.; Gorynin, I. and Nikos laev, V. (1997): Radiation Damage of Nuclear Power 
Plant Pressure Vessel Steel, Illinois: American Nuclear Society.

- Kryukov, A.; Debarberis, L.; Haehner, P.; Gillemot, F. and Oszvald, F. (2012): Thermal annealing as a method to predict results of high irradiation temperature embrittlement, Journal of Nuclear Materials, 432: 501.

- Fedotova, S.; Kuleshova, E.; Gurovich, B.; Frolov, A.; Maltsev, D.; Zhuchkov, G. and Fedotov I. (2018): APT-studies of phase formation features in VVER - 440 RPV weld and base metal in irradiationannealing cycles, Journal of Nuclear Materials, 511: 30 .

- Kryukov, A.; Sevikyan, G.; Petrosyan, V. and Vardanyan, A. (2014): Irradiation embrittlement assessment and prediction of Armenian NPP reactor pressure vessel steels, Nuclear Engineering and Design, 272: 28.

- Margolin, B.; Yurchenko, E.; Morozov, A; Pirogova, N. and Brumovsky, M. (2013): Analysis of a link of embrittlement mechanisms and neutron flux effect as applied to reactor pressure vessel materials of WWER, Journal of Nuclear Materials, 434: 347.

- Gillemot, F. (1995): The IAEA database ageing of reactor pressure vessel steels and welds. The IAEA Specialist Meeting on Irradiation Embrittlement and Mitigation / Espoo, Finland. 